Article

\title{
Genotoxicity of PM2.5 and PM1.0 Particulates on Human Periph- eral Blood Lymphocytes in Manila, Philippines
}

\author{
Ma. Katrina Gale Estonilo ${ }^{1}$, Joedith Anne Cazeñas ${ }^{1}$, Carlos Josef Villafuerte ${ }^{1}$, Custer Deocaris' ${ }^{2,3}$, Gloriamaris

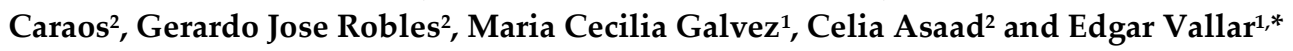
1 Applied Research for Community, Health, and Environment Resilience and Sustainability (ARCHERS), Center for Natural Science and Environment Research (CENSER), De La Salle University, Manila, Philip- pines; edgar.vallar@dlsu.edu.ph
2 Biomedical Research Unit, Atomic Research Division, Philippine Nuclear Research Institute, Department of Science and Technology, Diliman, Quezon City, Philippines
3 Research and Development Management Office, Technological Institute of the Philippines, Cubao, Quezon City, Philippines
* Correspondence: edgar.vallar@dlsu.edu.ph

\begin{abstract}
Urban air quality is increasingly being studied as a fraction of the world's population is now living in megacities. In this study, particulate matter (PM) along Taft Avenue, Manila, Philippines, is investigated in terms of its ability to induce genetic damage on human peripheral blood lymphocytes (PBL). Size-segregated roadside air samples were obtained from 2015-2016 near the university gate and analyzed using in vitro micronucleus and cytokinesis-block proliferation tests. While cellular proliferation was unaffected by $0-0.1 \mathrm{~kg} \cdot \mathrm{m}^{-3}$ of PM1.0 and PM2.5, PBL cells treated with $\mathrm{PM}_{2.5}$ displayed significantly higher micronucleus count $(\mathrm{p}=0.03)$ compared to the cells treated with $\mathrm{PM} 1.0$. Atomic Absorption Spectroscopy revealed greater amounts of $\mathrm{Cd}, \mathrm{Ca}, \mathrm{Pb}, \mathrm{K}, \mathrm{Na}$, and $\mathrm{Zn}$ in $\mathrm{PM}_{2.5}$ compared to $\mathrm{PM}_{1.0}$. The results indicate the differences in composition of the two size fractions of air particulates are associated with their genotoxicities.
\end{abstract}

Keywords: Particulate Matter; Genotoxicity; Peripheral Blood Lymphocytes; Atomic Absorption Spectroscopy; In-vitro Micronucleus Test

\section{Introduction}

Particulate matter (PM) are air particles comprising liquid or solid materials that are an admixture of organic and inorganic molecules. Common diameter sizes of PM are 1.0 $\mu \mathrm{m}, 2.5 \mu \mathrm{m}$, and $10 \mu \mathrm{m}$. Although the exact mechanisms are still being unravelled, air particulates have been linked to various diseases, from respiratory illnesses, cardiovascular to neurological disorders [1-3]. According to the Environmental Performance Index (EPI), the Philippines is ranked 114th out of 178 countries in poor implementation of environmental policies. In Manila, the average human exposure to $P M_{2.5}$ is $17 \times 10^{-9} \mathrm{~kg} \cdot \mathrm{m}^{-3}$, exceeding the $10 \times 10^{-9} \mathrm{~kg} \cdot \mathrm{m}^{-3}$ standard limit for $\mathrm{PM}_{2.5}$-exposure by the World Health Organization (WHO) [4]. The Philippines is among the top ten countries globally with the highest death burden due to air pollution which was estimated to account for 64,000 deaths in 2019 [5-6].

Biomonitoring of individuals exposed to high amounts of PM has been a subject of interest in the Philippines due to its heavy air pollution load, especially in its mega-cities [7]. Recolete and Villarino [8] assessed DNA damage to exfoliated buccal cells among 
urban street vendors in Iligan City that are considered at health risk due to significant exposures to vehicular exhaust. Vendors who are occupationally exposed to vehicular exhaust showed higher micronucleus frequency compared to a controlled group with $9.40 \pm 4.46$ and $4.80 \pm 3.25$, respectively. Similar genotoxicity trends were observed among gasoline station attendants and traffic enforcers in Manila [9]. While there are some studies conducted on DNA damaging effects of air pollution in the Philippines, a more detailed characterization of air particulate components is lacking. Hence, the purpose of this study is to analyze and differentiate the nuclear morphologies of human peripheral blood lymphocytes exposed to PM1.0 and PM2.5 fractions of air pollutants in Manila.

\section{Materials and Methods}

\subsection{Meteorological and air quality data at the sample site}

Average relative humidity (RH) was $63 \%$, and carbon monoxide level was 0.7 ppm throughout July 2015 to May 2016 during air sampling for PM1.o. Carbon monoxide and $\mathrm{RH}$ levels range from 0.11-0.13 and 69-76\%, from December 2016 to March 2017 during sampling for $\mathrm{PM}_{2.5}$.

\subsection{Collection and Extraction of the PM Samples}

The PM samples were collected using a MetOne E-sampler Instrument [10] and a Thermo Scientific Instruments TEOM for PM1.0 and PM2.5 [11] respectively; both were situated at De La Salle University (DLSU). Filters were readily available in time for the micronucleus assay. The researchers collected the filters of PM2.5 on December 1 and 12, 2016; January 23, 2017; February 7 and 28, 2017; and March 21, 2017. For PM1.0, the team collected the filters between July 2015 - December 3, 2015, and December 3, 2015 - May 2, 2016. Particulate matter was manually scraped from the air filters and weighed. The recorded weights were $9.5 \times 10^{-6} \mathrm{~kg}$ and $6.7 \times 10^{-6} \mathrm{~kg}$ for PM1.0 and PM2.5.

\subsection{In-Vitro Micronucleus Assay}

Each PM sample was combined with PB Max Karyotyping Medium (Gibco) to produce a stock solution of the PM. The stock solution was diluted to different PM treatment doses, namely $0.05 \mathrm{~kg} \cdot \mathrm{m}^{-3}, 0.1 \mathrm{~kg} \cdot \mathrm{m}^{-3}$, and $0.15 \mathrm{~kg} \cdot \mathrm{m}^{-3}$. A volume of $0.5 \times 10^{-6} \mathrm{~m}^{3}$ of blood was added to $4.5 \times 10^{-6} \mathrm{~m}^{3}$ of PB-Max Karyotyping Medium with the PM sample. Peripheral blood lymphocytes were cultured in a $5 \% \mathrm{CO}_{2}$ environment at $37{ }^{\circ} \mathrm{C}$. After 24 hours, $21 \times 10^{-9} \mathrm{~m}^{3}$ of Cytochalasin B was introduced to the sample, and after 68-72 hours, the culture was harvested. Samples were then placed in a centrifuge at 1200 RPM for 10 minutes. The supernatant was removed from the culture medium and was treated by $7 \mathrm{x}$ $10^{-6} \mathrm{~m}^{3}$ of cold $(277.15 \mathrm{~K}) 0.075 \mathrm{M} \mathrm{KCl}$ to lyse red blood cells. Again, it was placed in a centrifuge with the same settings and instead treated with $5 \times 10^{-6} \mathrm{~m}^{3}$ fixative composed of methanol and acetic acid (10:1 ratio) and combined with Ringer's solution one is to one ratio. Steps were repeated about two to three times until the cell suspension is clear. After removing the supernatant to $1 \mathrm{~cm}$ or less above the cell pellet, the suspension was dropped onto a clean glass slide and was stained with 2 - 6\% Giemsa after drying. Staining was done for about 10 - 20 minutes. Slides were then rinsed with distilled water.

MN analysis was done through light microscopy using an Olympus BX15 Microscope and Nikon DS-Fi3 with 20x magnification for efficient counting. Criteria given by the TG-487 were followed in this study. As stated in the TG-487 [12], at least 1000 binucleated cells were counted for the MN frequency per treatment, along with the negative control. One thousand cells were scored per replicate per treatment. The equation

$$
M N \text { Frequency }=\frac{\text { Number of } B N \text { cells with } M N}{\text { Total number of cells }} \times 100
$$


was used to obtain the MN frequency of each treatment per PM size fraction. Two replicates were done for each dose and each PM size. A review panel at the Center for Natural Science and Environment Research (CENSER), DLSU approved the research protocol following the guidelines of the University Research Ethics Committee. The research was conducted under the supervision of a licensed biomedical practitioner of the Philippine Nuclear Research Institute.

\subsection{Statistical Analysis of Micronucleus Assay}

One-way ANOVA with Tukey-Kramer HSD test was used to evaluate the results for each dose and PM size from the micronucleus assay. The MN frequencies obtained from the two replicates of each dose of each PM size were used to evaluate the genotoxicity of each concentration of PM. The MN frequencies of each dose were then compared to the negative control with a confidence level of $99 \%$ ( $p \leq 0.01)$. Tukey-Kramer was then used to identify which treatment pairs were significantly different. A confidence level of $99 \%$ $(\mathrm{p} \leq 0.01)$ was also used for the post hoc test.

To compare $\mathrm{MN}$ frequencies of all the concentrations of $\mathrm{PM}_{1.0}$ and $\mathrm{PM}_{2.5}$, two-way ANOVA was used with a statistical significance of less than 0.05 ( $p \leq 0.05)$. Note that the $0.15 \mathrm{~kg} \cdot \mathrm{m}^{-3}$ of PM1.0 was not included in the two-way ANOVA because no binucleate cells were found. Binucleate cells with micronucleus were found in the $0.15 \mathrm{~kg} \cdot \mathrm{m}^{-3}$ concentration of PM2.5. STATISTICA was used for all the statistical analyses done for this study.

\section{Results}

The size and chemical composition of PM play differentiating roles in the adverse health effects of air pollution. Since the penetration depth and deposition of PM in the pulmonary and circulatory system is particle-size dependent, we evaluated the DNA damaging effects between the two respirable size fractions: PM2.5 (fine particulates) and PM1.0 (ultrafine particulates). In a review by Xing et al. [13], several studies point out that $\mathrm{PM}_{2.5}$ is harmful to the respiratory system. A meta-analysis conducted by Huang et al. [14] studying the relationship between $\mathrm{PM}_{2.5}$ exposure and lung cancer incidence revealed that Asia has the highest lung cancer incidence correlated with PM2.5.

On the other hand, $\mathrm{PM}_{1.0}$ is deposited in the alveolar, tracheobronchial compartments and can even enter the bloodstream. With such a biological fate, PM1.0 is likely to present a more complex set of health risks. For example, Sanchez-Guerra et al. [15] showed that exposure of human blood to PM1.0 sampled from air pollutants in Beijing induced DNA methylation that has the potential to trigger carcinogenesis. DNA methylation events can inhibit the expression of tumor-suppressing genes that eventually initiate cancer development [16].

\subsection{Differential Genotoxicity of PM2.5 and PM1.0}

Figure 1 shows the MN frequencies of human peripheral blood lymphocytes that were exposed to different concentrations of PM1.0 and PM2.5. Based on the p-values obtained, there was a significant difference in the induction of micronuclei between PM1.0 and PM2.5. Two-way ANOVA showed that PM2.5 was more genotoxic compared to PM1.0 at $p=0.03$. No result was obtained at $0.15 \mathrm{~kg} \cdot \mathrm{m}^{-3}$ concentration for $\mathrm{PM}_{2.5}$ because the level resulted in cytotoxicity.

Figure 2, on the other hand, shows the results of the CBPI (cytokinesis-block proliferation index) count at each concentration of the PM size fractions. There was no significant difference between the CBPI at each treatment concentration, regardless of the sizefraction, indicating that the range of concentrations used for PM1.0 did not affect cell proliferation. PM2.5, on the other hand, was also non-toxic to the cells from $0.05-0.01 \mathrm{~kg} \mathrm{~m}^{-3}$. 

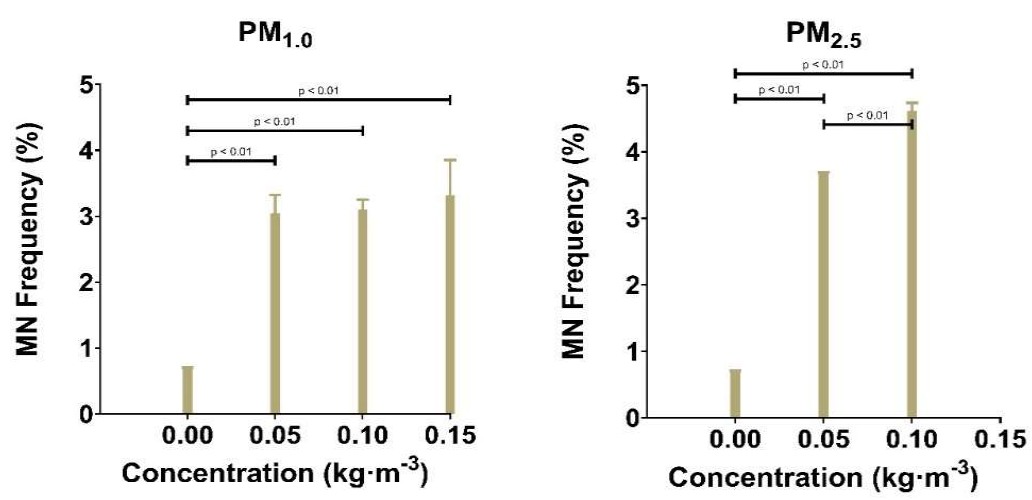

Figure 1. MN frequency of the two PM size fractions. Only the p-values which yielded a significant difference are shown.

$\mathrm{PM}_{1.0}$

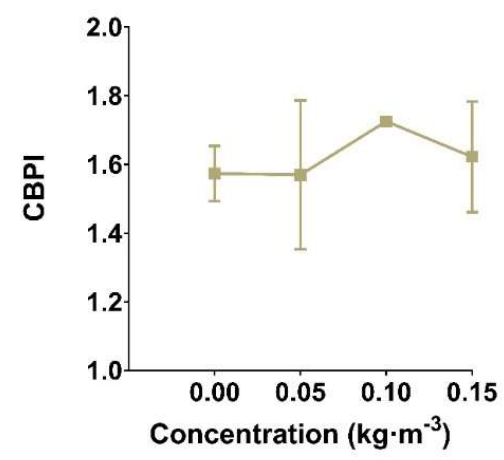

$\mathrm{PM}_{2.5}$

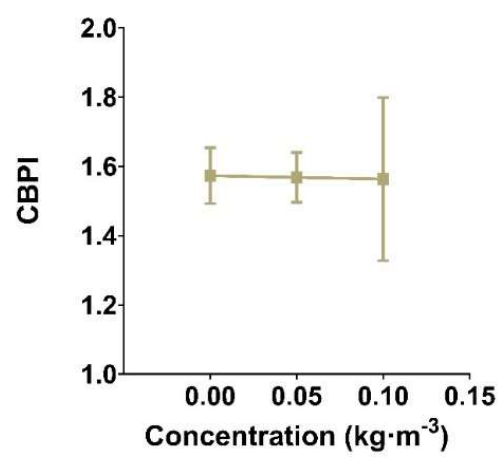

Figure 2. CBPI counts obtained from both PM size fractions.

To further confirm cell proliferation was not affected throughout the concentration range, nuclear morphologies of the cells were assessed. Cell counts of mono, bi-, and polynucleated lymphocytes did not significantly differ across the different concentrations for both PM1.0 and PM2.5 (Figure 3). Thus, except for the highest concentration used for PM2.5, cell viability was not affected by the level of analyte used in the experiment. The observations were attributed to the differential genotoxic effects of the two classes of PMs. 

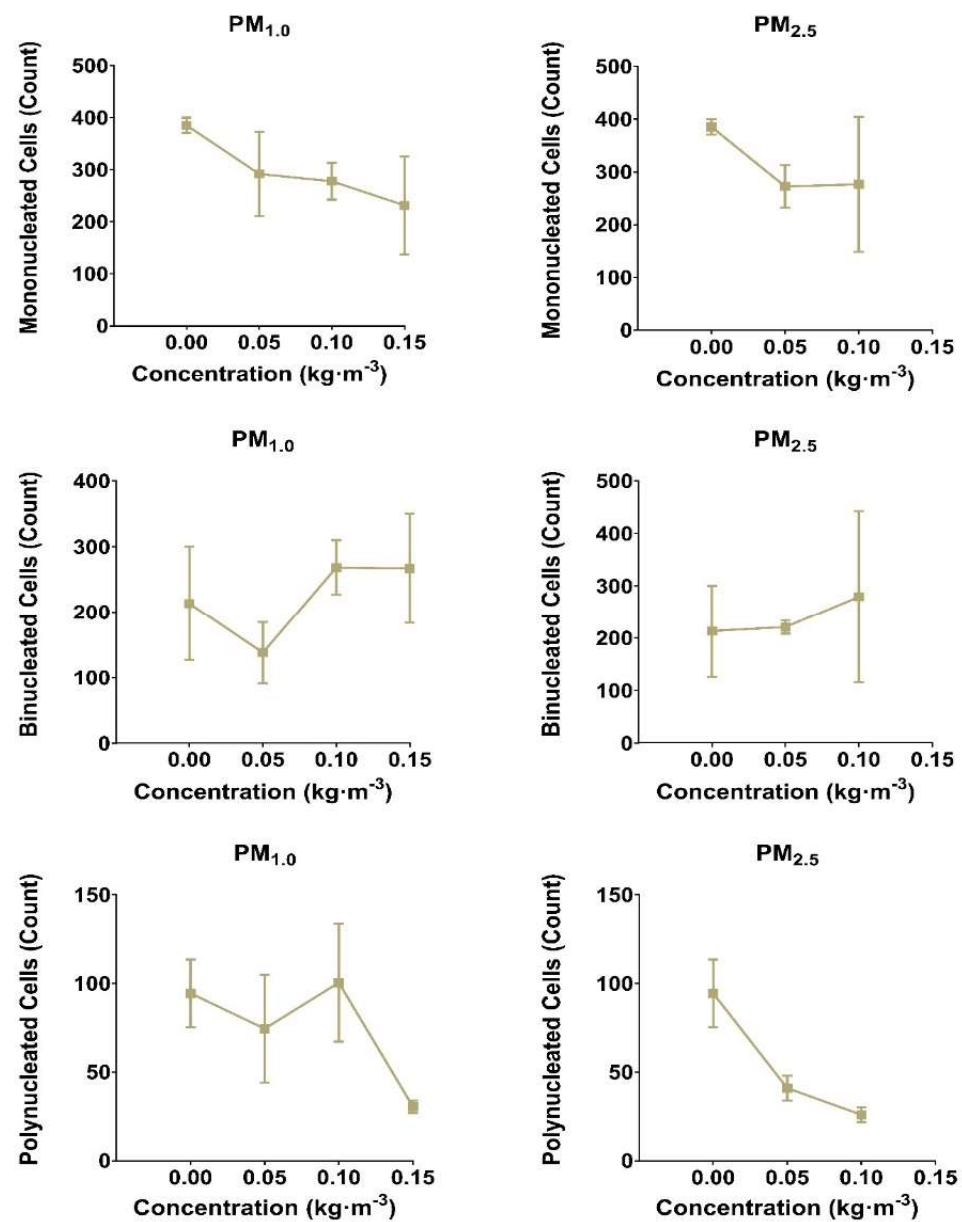

Figure 3. Cell count profile for both $\mathrm{PM}_{1.0}$ and $\mathrm{PM}_{2.5}$.

\subsection{Differences in the heavy metal compositions}

The exact chemical nature of the PM fractions that showed different genotoxic activities is still unclear. Since trace metal species from vehicular exhaust emitted into the atmosphere can cause various health-related problems, the presence of heavy metals in the samples was studied. Cadmium $(\mathrm{Cd})$, Lead $(\mathrm{Pb})$, and $\mathrm{Zinc}(\mathrm{Zn})$ were found in both PM size fractions. Calcium $(\mathrm{Ca})$, Potassium $(\mathrm{K})$, and Sodium $(\mathrm{Na})$ were also found in the samples used for the AAS analysis. Consistent with the pattern of genotoxicity, the concentrations of the heavy metals, particularly of $\mathrm{Pb}$, are higher in $\mathrm{PM}_{2.5}$ compared to $\mathrm{PM}_{1.0}$ (Table 1). Since most vehicle exhaust is already lead-free in the Philippines, it is suspected that the trace amounts of lead may originate from second-and third-hand smoke, resuspended soil, and lead-acid car batteries [17].

Table 1. Comparison of the elemental composition. Estimated Method Detection Limit (EMDL) indicates the lowest possible concentration that can be detected. Estimated Limits of Quantitation (ELOQ) is an indication of a high probability of the element in the sample.

\begin{tabular}{ccc}
\hline Elements & PM1.0 & PM $_{2.5}$ \\
\hline $\mathrm{Cd}\left(\mathrm{mg} \cdot \mathrm{L}^{-1}\right)$ & $<$ EMDL $(\mathrm{EMDL}=0.5)$ & $<\mathrm{EMDL}(\mathrm{EMDL}=0.5)$ \\
$\mathrm{Ca}\left(\mathrm{mg} \cdot \mathrm{L}^{-1}\right)$ & $50(\mathrm{ELOQ}=50)$ & $40(\mathrm{ELOQ}=50)$ \\
$\mathrm{Pb}\left(\mathrm{mg} \cdot \mathrm{L}^{-1}\right)$ & $<\mathrm{EMDL}(\mathrm{EMDL}=2)$ & $5(\mathrm{ELOQ}=7)$ \\
$\mathrm{K}\left(\mathrm{mg} \cdot \mathrm{L}^{-1}\right)$ & 1440 & 2100 \\
$\mathrm{Na}\left(\mathrm{mg} \cdot \mathrm{L}^{-1}\right)$ & 2800 & 2770 \\
\hline
\end{tabular}




$\mathrm{Zn}\left(\mathrm{mg} \cdot \mathrm{L}^{-1}\right) \quad 3(\mathrm{ELOQ}=4) \quad 3(\mathrm{ELOQ}=4)$

\section{Conclusions}

Based on the dose-dependent increase in micronuclei frequency of peripheral blood lymphocytes exposed to PM1.0 and PM2.5, air pollutants in Manila may have the potential to lead to long-term DNA damage. $\mathrm{PM}_{2.5}$ appears to show higher levels of cell toxicity relative to PM1.o. This finding is consistent with the elemental signature of the samples where heavy metal concentrations, particularly of lead, are higher in $\mathrm{PM}_{2.5}$ compared to PM1.o.

Author Contributions: Conceptualization, M.E., J.C., C.V., E.V. and C.D.; methodology, G.C., G.R., C.A.; formal analysis, M.E., J.C., C.V., E.V., M.G. and C.D.; investigation, M.E., J.C., C.V., E.V. and C.D.; resources, M.E., J.C., C.V., and E.V.; writing-original draft preparation, M.E., J.C., C.V.; writing - review and editing, E.V., M.G. and C.D.; supervision, E.V. All authors have read and agreed to the published version of the manuscript.

Funding: This research received no external funding.

Institutional Review Board Statement: Ethical review and approval were waived for this study-

Informed Consent Statement: Informed consent was obtained from the subjects involved in the study.

Conflicts of Interest: The authors declare no conflict of interest.

\section{References}

1. Kyung, S.; Jeong, S. Particulate-Matter Related Respiratory Diseases. Tuberc Respir Dis 2020, 83(2), 116-121, https://doi.org/10.4046/trd.2019.0025.

2. Hahad, O.; Lelieveld, J.; Birklein, F.; Lieb, K.; Daiber, A.; Münzel, T. Ambient Air Pollution Increases the Risk of Cerebrovascular and Neuropsychiatric Disorders through Induction of Inflammation and Oxidative Stress. Int J Mol Sci 2020, 21(12), 4306, https://doi.org/10.3390/ijms21124306.

3. Miller, M. Oxidative stress and the cardiovascular effects of air pollution. Free Radic Biol Med 2020, 151, 69-87, https://doi.org/10.1016/j.freeradbiomed.2020.01.004.

4. World Health Organization. Health Aspects of Air Pollution with Particulate Matter, Ozone and Nitrogen Dioxide. Available online: https://www.euro.who.int/ data/assets/pdf file/0005/112199/E79097.pdf (accessed on 02 October 2021).

5. Narain, U.; Sall, C. Methodology for Valuing the Health Impacts of Air Pollution : Discussion of Challenges and Proposed Solutions. World Bank, Washington, DC. (C) World Bank. 2016. https://openknowledge.worldbank.org/handle/10986/24440 License: CC BY 3.0 IGO.

6. Macatangay, L.; Hernandez, R. "A Deep Learning-Based Prediction and Simulator of Harmful Air Pollutants: A Case from the Philippines," 2020 11th IEEE Control and System Graduate Research Colloquium (ICSGRC), 2020, 381-386, https://doi:10.1109/ICSGRC49013.2020.9232528.

7. Stahl, C.; Cruz, M.T.; Bañaga, P.A. et al. An annual time series of weekly size-resolved aerosol properties in the megacity of Metro Manila, Philippines. Sci Data 2020, 7, 128, https://doi.org/10.1038/s41597-020-0466-y.

8. Recoleto, K.; Villarino, A. Micronucleus Test in Exfoliated Buccal Cells of Female Street Vendors Exposed to Vehicular Exhaust in Iligan City, Philippines. Int. j. humanit. soc. sci. 2017, 9(2), 119-130.

9. Hallare, A.; Gervasio, M.; Gervasio, P.; Acacio-Claro, P. Monitoring genotoxicity among gasoline station attendants and traffic enforcers in the City of Manila using the micronucleus assay with exfoliated epithelial cells. Environ. Monit. Assess. 2008, 156(14), 331-341, https://doi.org/10.1007/s10661-008-0488-y.

10. Specifications E-SAMPLER. Available online: https://metone.com/wp-content/uploads/pdfs/e-sampler.pdf (accessed on 02 October 2021).

11. 1405-D TEOM ${ }^{\mathrm{TM}}$, Continuous Dichotomous Ambient Particulate Monitor. Available online: https://www.thermofisher.com/order/catalog/product/TEOM1405D?ICID=search-\%20product\#/TEOM1405D?ICID=search-\%20product (accessed on 02 October 2021).

12. Test No. 487: In Vitro Mammalian Cell Micronucleus Test. 2014. “OECD Guidelines for the Testing of Chemicals”, Section 4. Available online: https://doi.org/10.1787/9789264264861-en (accessed on 02 October 2021).

13. Xing, Y.; Xu, Y.; Shi, M.; Lian, Y. The impact of PM2.5 on the human respiratory system. J. Thorac. Dis. 2016, 8(1), E69-E74, http://doi.org/10.3978/j.issn.2072-1439.2016.01.19. 
14. Huang, F.; Pan, B.; Wu, J.; Chen, E.; Chen, L. Relationship between exposure to $\mathrm{PM}_{2.5}$ and lung cancer incidence and mortality: A meta-analysis. Oncotarget. 2017, 8, 43322-43331, https://doi.org/10.18632/oncotarget.17313.

15. Sanchez-Guerra, M.; Zheng, Y.; Osorio-Yanez, C.; Zhong, J.; Chervona, Y.; Wang, S.; Chang, D.; McCracken, J.; Diaz, A.; Bertazzi, P.; Koutrakis, P.; Kang, C.; Zhang, X.; Zhang, W.; Byun, H.; Schwartz, J.; Hou, L.; Baccarelli, A. Effects of particulate matter exposure on blood 5-hydroxymethylation: Results from the Beijing truck driver air pollution study. Epigenetics 2015, 10(7), 633642, https://doi.org/10.1080/15592294.2015.1050174.

16. Wajed, S.; Laird, P.; DeMeester, T. DNA Methylation: An Alternative Pathway to Cancer. Ann. Surg. 2001, 234(1), 10-20, https://doi.org/10.1097/00000658-200107000-00003.

17. World Health Organization. Lead poisoning and health. Available online: http://www.who.int/mediacentre/factsheets/fs379/en/ (accessed on 28 October 2021). 